\title{
Grey correlation analysis on factors affecting industrial water pollution in Jiangsu Province
}

\author{
Aixiang Tao \\ School of Management and Economy \\ HuaiYin Institute of Technology \\ Huai an, China \\ Taxzfytq@sina.cn
}

\begin{abstract}
Keywords: grey correlation of industrial water pollution in Jiangsu
Abstract: Industry is the main industry of water pollution.we should reduce the total amount of industrial water pollution to enhance the overall quality of the environment . Taking Jiangsu as an example, this paper analyzes the factors that affect the industrial water pollution by using the grey correlation analysis method. The results show that, in accordance with the influence factors for industrial water pollution from big to small order, influence factors are as follows: Engineering and technical personnel number; industrial wastewater treatment investment; industrial energy consumption; industrial electricity consumption;gross value of industrial output. Therefore, to enhance the Jiangsu Province's industrial wastewater pollution control level,we need to focus on following aspects:increasing number of engineering and technical personnel; the increase in investment in industrial wastewater treatment.we also need to take effective measures to reduce industrial energy use and industrial use of electricity.
\end{abstract}

\section{Introduction}

Industrial water pollution is an important part of water pollution in our country. Upgrading the level of industrial wastewater pollution control is of great importance to enhance the overall environment. In recent years, some scholars have made an analysis on the influence factors of industrial water pollution and have drawn some scientific conclusions. Xie Hongbin and Liu Zhaode's studies show that, the following aspects have a great impact on industrial wastewater pollution: industrial restructuring, industrial technology progress;industrial wastewater discharge standards [1]. Zhang Yuan and Wu Feng Ping's research results show that, the main factors affecting industrial water pollution are as follows: technological progress; industrial economic growth;emission factor effect;effect of industrial structure;the size of the population [2]. Zhou Jing and Yang Guishan have proved that,economic growth and industrial wastewater discharge has a high correlation each other [3]. Luo Haijiang's study shows that,technical factors and industrial output value of industrial wastewater discharge has a significant impact on industrial wastewater pollution [4]. He Xiaoqing finds that,industrial agglomeration makes industrial wastewater discharge more concentrate in space, while the level of industrial wastewater treatment technology helps to improve the level of this trend[5].

\section{Modeling Steps with Grey Relational Analysis}

A. The establishment of the original series and dependent variables refer to the number of columns 
and compare the number of independent variables listed

Refer to the number of columns known as the dependent variable sequences recorded as the mother; $x_{0}^{(k)}: x_{0}^{(k)}=\left[x_{0}^{(1)}, x_{0}^{(2)}, x_{0}^{(3)}, \ldots, x_{0}^{(k)}\right]$

Comparing the number of independent variables is also called the sub-sequence of the column, $x_{i}^{(k)}: x_{i}^{(k)}=\left[x_{i}^{(1)}, x_{i}^{(2)}, x_{i}^{(3)}, \ldots, x_{i}^{(k)}\right](i=1,2,3, \ldots, n)$

B. the original sequence is to be treated of non-dimensional

The purpose is to eliminate the impact of different sizes and to facilitate calculation and comparison.

initialize method and the average method Can be used. calculate formulas are

$$
x_{i}^{\left(k^{\prime}\right)}=x_{i}^{(k)} / x_{i}^{(1)} \text {; or }
$$

$x_{i}^{\left(k^{\prime}\right)}=x_{i}^{k} / \overline{x_{i}}$

C.calculate the absolute value between parent sequence and each sub-sequence at each time point to identify the biggest difference and minimum difference

difference sequence:

$$
\Delta_{i}(k)=\left|x_{0}^{\left(k^{\prime}\right)}-x_{i}^{\left(k^{\prime}\right)}\right|(i=1,2,3, \ldots, n)
$$

The biggest difference:

$$
\Delta \max =\max \underset{i}{\operatorname{ax}} \max _{i}\left|x_{0}^{\left(k^{\prime}\right)}-x_{i}^{\left(k^{\prime}\right)}\right|
$$

the minimum difference:

$$
\Delta \min =\min _{i} \min _{i}\left|x_{0}^{\left(k^{\prime}\right)}-x_{i}^{\left(k^{\prime}\right)}\right|
$$

D.calculate the Gray correlation coefficient

$L_{0 i}^{(k)}=\frac{\Delta \min +\lambda \Delta_{\max }}{\Delta_{i}(k)+\lambda \Delta_{\max }}$

Among these , $L_{0 i}^{(k)}$ is Gray correlation coefficient between the number of

sub-sequences and the parent sequence, $\quad \lambda$ is distinguish factors, usually between 0 and 1 .

E. Calculation of gray correlation degree

The overall correlation need to take the different observation points in the overall level of the importance of observation into account, therefore need to determine the weight of each point. Under normal circumstances, using the arithmetic mean method to calculate the grey correlation degree.

$$
r_{0 i}=1 / n \sum_{k=1}^{n} r_{0 i}(k)
$$

$r_{0 i}$ represent the correlation coefficient between $x_{0}$ and $x_{i}$.

F. sort the correlation degree

Correlation is sorted based on size of order. The bigger a correlation is the bigger the relation degree between the mother sequence and sub-sequence.According to experience, when the correlation is greater than 0.6 ,it will be considered a significant association ${ }^{[6-7]}$.

\section{Index Choice and Calculation}

\section{A. Index Choose}

In this paper, the industrial wastewater discharge quantity is used as a general index to measure the degree of industrial water pollution in Jiangsu Province,which was denoted as A(unit: 100 million 
tons). Factors that affect the industrial wastewater discharge quantity in Jiangsu Province are as follows: total industrial output value (unit: hundred million yuan,denoted as B1); industrial energy consumption quantity (unit: ten thousand tons of standard coal, denoted as B2), industrial electricity quantity (unit: hundred million kwh, denoted as B3); engineering and technical personnel quantity (unit: 10000 people, denoted as B4); industrial wastewater treatment investment capital (unit: RMB 100 million yuan, denoted as B5). Specific data are as follows:

Table 1 the original data of the industrial wastewater pollution and its affecting factors

\begin{tabular}{|l|l|l|l|l|l|l|l|}
\hline & 2007 & 2008 & 2009 & 2010 & 2011 & 2012 & 2013 \\
\hline A & 26.88 & 25.93 & 26.74 & 26.38 & 24.63 & 23.61 & 22.06 \\
\hline B1 & 59576.7 & 69486.3 & 73871.6 & 86320.4 & 104736.4 & 111202.3 & 116027.8 \\
\hline B2 & 17307.2 & 18133.5 & 19260.3 & 20597.8 & 22013.3 & 22636.4 & 22548.9 \\
\hline B3 & 2415.5 & 2502.7 & 2631.3 & 3052.1 & 3385.2 & 3562.5 & 3794.2 \\
\hline B4 & 20.03 & 19.72 & 19.67 & 19.00 & 19.82 & 19.79 & 10.99 \\
\hline B5 & 15.22 & 19.81 & 14.54 & 7.44 & 15.20 & 9.96 & 13.41 \\
\hline
\end{tabular}

B. Calculation

According the above steps, the results are as follows:

Table 2 grey relation coefficient between the industrial wastewater pollution degree and its affecting factors

\begin{tabular}{|l|l|l|l|l|l|}
\hline & B1 & B2 & B3 & B4 & B5 \\
\hline A & 0.580 & 0.734 & 0.693 & 0.895 & 0.799 \\
\hline
\end{tabular}

According the importance, the grey relation coefficient are as follows

$\mathrm{B} 4>\mathrm{B} 5>\mathrm{B} 2>\mathrm{B} 43>\mathrm{B} 1$

\section{Conclusion and Advice}

From the calculation above, we can see that, the most important factor affecting the discharge of industrial wastewater in Jiangsu province is the number of engineering and technical personnel. The number of engineering and technical personnel represents the level of technical application in the industrial field. It can be seen that, the technical level of the industrial industry directly affects the discharge of industrial waste water. Because the person which master the advanced technology can use advanced science and technology to reduce industrial waste water discharge.

Second important factors affecting industrial pollution is the investment in industrial wastewater treatment. When the investment in industrial wastewater treatment is increased,it is convenient for the introduction of advanced equipment and advanced wastewater treatment technology. Therefore, it can help to effectively reduce the discharge of industrial wastewater.

Industrial energy consumption is the third factor that affects the discharge of industrial waste water in Jiangsu. At present, the extensive mode of production in our country has not fundamentally changed. In the process of industrial production, energy consumption is too large. This not only lead to a lot of waste generation, but also lead to a large number of waste. Therefore, we should take scientific measures to reduce energy consumption in the industrial field, which helps to reduce industrial waste water discharge.

Industrial power consumption also has a significant impact on industrial wastewater discharge. At present, the efficiency of China's industrial field is not high, while the use quantity of industrial electricity has grown quickly. High power consumption in the process of industrial production leads to more pollutants.at the same time, more industrial waste water is produced. Therefore, we should use more advanced equipment and establish more perfect system to further reduce the size of the 
industrial use of electricity. This will help reduce emissions of industrial wastewater.

The gross industrial output value has a certain influence on the discharge of industrial wastewater. During the process of industrial output, more raw materials will inevitably be used.Therefore, more waste water is produced. We should pay attention to improving the quality of industrial production in the process of steadily increasing the gross industrial output value. We should gradually reduce the high energy consumption and high pollution industrial production.Meantime , we should increase the production of high-tech industries. This plays an important role in reducing the pollution of industrial waste water.

\section{Reference}

[1]XIE Hongbin,LIU Zhaode.Quantitative Analysis on the Influential Factors of Industrial Waste Drainage.Resources and Environment in the Yangtze Basin, 2004(7):395-398

[2]ZHANG Yuan,WU Fengping.Study on the Effect of Decomposition Factors of Industrial Wastewater Discharge in China Based on LMDI Method. Industrial Economy Research,2015(6):99-103

[3]ZHOU Jing, YANG Guishan.Study on the Rvolvement of the Relationship between Industrial Wastewater Discharge and Economic Growth in Jiangsu Province.Geographical Research,2007,26(9):932-936

[4]LUO Haijiang.Spatial Coupling of Economic Development and Pollution Emission:Taking Industrial Wastewater for Example.Ecology and Environment Sciences,2013,22(7):1199-1203

[5]HE Xiaoqing.Study on Factors Affecting Spatial Evolution of Industrial Water Pollution in China.Resource Development \& Market,2016,32(5):540-545

[6]Liusifeng,Guotianbang.The grey system theory and its application[M].Zhengzhou:Henan university press,1991(2)

[7]Yidesheng,Guoping.grey theory and method[M].Beijing:oil industry press,1992(1) 